\title{
Metaphors and Euphemisms of Death in Akan and Hebrew
}

\author{
Charles Owiredu \\ Daniel Institute, Central University, Accra, Ghana \\ Email: charles.owiredu@centralgospel.org,prof.owiredu@gmail.com
}

How to cite this paper: Owiredu, C. (2020). Metaphors and Euphemisms of Death in Akan and Hebrew. Open Journal of Modern Linguistics, 10, 404-421.

https://doi.org/10.4236/ojml.2020.104024

Received: July 2, 2020

Accepted: August 25, 2020

Published: August 28, 2020

Copyright (C 2020 by author(s) and Scientific Research Publishing Inc. This work is licensed under the Creative Commons Attribution International License (CC BY 4.0).

http://creativecommons.org/licenses/by/4.0/

\begin{abstract}
In this paper, we analyze, contrastively, Akan and Hebrew euphemistic expressions for death using the theoretical framework of the Conceptual Metaphor Theory espoused by Lakoff and Johnson (1980). This cognitive approach enables to demonstrate the mitigating power of metaphors used as a dynamic source for euphemistic reference with the ability to conceal offensive and taboo aspects of the target domain. We have put various Akan and Hebrew euphemisms into five categories of death metaphors with the aim to contrastively establish similarities and differences in the conceptualization of death in the two languages. Our intention is to demonstrate how metaphors are employed as euphemistic device for speaking indirectly, unprovocatively and respectfully about death. This study specifically reveals how the Akan and Hebrew cultures, defined by their respective languages, share the same attitude to death.
\end{abstract}

\section{Keywords}

Akan, Hebrew, Cognitive Linguistics, Conceptual Metaphor, Euphemism, Death, Old Testament

\section{Introduction}

The term "cognitive linguistics" has been employed to refer to an inter-disciplinary branch of linguistics that combines knowledge and research from linguistics and psychology. Ungerer \& Schmid (1996: p. F36) define cognitive linguistics as "an approach to language that is based on our experience of the world and the way we perceive and conceptualize it." Conceptual metaphor, in cognitive linguistics, refers to understanding one idea in terms of another, for example, understanding time in terms of money (e.g. "I spent several hours on my studies yesterday"). The idea of conceptual metaphor was first extensively explored by Lakoff 
and Johnson (1980) in their book, Metaphors We Live By. In the last four decades, the field of metaphor research within the broader discipline of cognitive linguistics has developed extensively.

According to Lakoff and Johnson (1980: p. 3), "metaphor is pervasive in everyday life, not just in language but in thought and action." Their assertion contradicts the view which generally held that metaphor is simply a decorative device that is confined to literature, rhetoric and art. Generally, many of our everyday thought and speeches are interlaced with metaphorical expressions. Evans and Green (2007: p. 286) confirm this by stating that "the basic premise of Conceptual Metaphor Theory is that, metaphor is not simply a stylistic feature of language, but that thought itself is fundamentally metaphorical in nature." In both Akan and Hebrew, many speeches are metaphorically structured.

The core principle of the Conceptual Metaphor Theory is that metaphor is view as a cross-domain mapping of our conceptual system. Their theory allows us to comprehend one aspect of a concept in terms of another (Lakoff \& Johnson, 1980: p. 10). Kövecses (2002: p. 79) adds that "[w]hen a source domain is applied to a target, only some aspects of the target are brought into focus."

In every society, there are taboo expressions, doped with concepts that are considered too offensive, crude or frightening. Metaphors may conceal, deny or even mitigate aspects of those concepts that may cause fear, and social embarrassment. Thus, metaphor-based euphemisms may aid in highlighting less disturbing, less vulgar, less frightening, or less blunt aspects of such concepts. It is in this context that conceptual metaphors help in systematically mapping the structure of the source domain (the realm of concrete reality) onto the structure of the target domain (the taboo of death, in this case). This is better clarified by Fan (2006: p. 72) in observing that linguistic expressions in the source domain, by which he means euphemistic expressions, are used to replace taboo expressions in the target domain.

It is evident that death taboos can be analyzed in terms of conceptual metaphors. Granted that a death-related target concept can be expressed by different source domains (Kövecses, 2003: p. 79), the connotations of source domain are used to refer to target concept influences, to a great extent, the euphemistic force of the metaphorical substitute. An example is the taboo of death, which is subject to different conceptualizations through the metaphorical equations DEATH IS LOSS, DEATH IS A JOURNEY, DEATH IS SLEEP, DEATH IS THE END and DEATH IS A PERSON, which are all the subjects for discussion in this paper.

Lakoff and Johnson (1980: p. 3) define metaphor as understanding and experiencing one kind of thing in terms of another or as a tightly structured mapping or set of correspondences between two conceptual domains, which they refer to as the source and target domains. Source domain refers to the conceptual domain from which metaphorical expressions are drawn (e.g. death is a journey). Target domain refers to the conceptual domain we try to understand (e.g. death is a journey). Mapping, in relation to conceptual metaphor, is the way in which a 
source domain tracks unto the target domain. Thus, conceptual metaphors employ a more abstract concept as target and a more concrete concept as their source. For instance, the Akan metaphor, "owuo kura adec mu a nkwa ntumi ngye", "when death lays hold on a thing, life cannot take it back", relies on a more concrete concept, thus expressing the human being as a SUBSTANCE/OBJECT that death, as a PERSON, has snatched from life as a PERSON. Here, as the original owner of the "person" is LIFE, DEATH dispossess LIFE. Death becomes a DISPOSSESSOR. Therefore, in the metaphor DEATH IS A DISPOSSESSOR, the target domain is death wand the source domain in dispossessor.

The Akan people form more than $50 \%$ of the population of Ghana. The Akan language is the most predominant language in Ghana, spoken by almost 70\% of Ghanaians, including Akan and non-Akan tribes. There are more readers of the Bible translations in the Akan dialects (Twi and Fante) than any other language in Ghana. This makes relevant, any study that looks at the various expressions in both the Akan language vis a vis similar expression in the original languages of the Bible. In this study, using for the theoretical framework, the Conceptual Metaphor theory, initiated by Lakoff and Johnson (1980), we analyze euphemistic expressions for death in Akan everyday language and the Hebrew Bible.

Whilst researchers such as Gibbs and Steen (1999), Lakoff (1987); Pfaff, Gibbs and Johnson (1997); Murphy (2001), Agyekum (2010), Nyakoe et al. (2012), Otoo (2017) among others, have done extensive work on the Conceptual Metaphor Theory, not much research has been done on metaphors as a euphemistic device in relation to death. To the best of my knowledge, relatively, not much attention has been paid to conceptual metaphor in relation to similarities and differences between euphemistic expressions for death in the Akan Language of Ghana and in the Bible. This paper aims at establishing whether DEATH metaphors derived from Akan euphemistic expressions may hold in the Biblical Hebrew language. We will also make an attempt to establish whether Akan uses any other metaphors for euphemistic reference to death that cannot be found in Hebrew.

Akan speakers use this death as sleep metaphor to console themselves that their departed loved one will wake up in the next life stronger and in a better position to support the living. This is confirmed in some of their dirges heard at Akan funerals where the mourners ask the just departed soul to carry a message of the long departed in the world of the dead, that they the living are in need and so the dead should send relief to them.

Akan euphemisms for death can be put in two categories. The first 1) those which directly refer the survivor's condition. One example is ade ato m'ani, "something has fallen into my eye". This euphemism is an expression of the pain and grief death brings to the bereaved, which is made evident in the redness of the eyes. Thus, DEATH IS AN OBJECT in the eye of the mourner. Another expression is sman nsa nifa apan, "the right hand of the state is dislocated". The right is conceived as being superior to the left. It symbolizes the position of power. The king as the right hand of the sate indicates his power as ruler. In his 
death, therefore, the state becomes "HANDLESS", in other words, his subjects become powerless, unstable and vulnerable.

The second category 2) is that which refers to the condition or conceptualized experience of the deceased. These are the euphemistic expressions that portray the deceased as resting, embarking on a journey or even working. The aim of this paper is to explore Akan and Hebrew euphemisms that have to do with the state of the deceased and its experience.

Having introduced the subject of this paper, the next section discusses the methodology and theoretical framework for the study, then proceeds to explore euphemism and the taboo of death. After which section, it looks at a contrastive approach to understanding Akan and Hebrew metaphors for death and ends with a concluding summary.

\section{Methodology and Theoretical Background}

This study was conducted in Accra among Akan speaking people. Data was gathered by sampling ten Akan speakers. Each respondent was required to mention at least four euphemistic expression used in everyday life when referring to death. At the end of the interviews twenty-one (21) different Akan euphemistic substitutes were realized. The number of Hebrew euphemistic substitutes selected from the Old Testament Hebrew Bible was sixteen (16).

This paper is based on theoretical assumptions derived from the Conceptual Metaphor Theory of Lakoff and John (1980). The cognitive approach adopted by this paper claims that metaphor is [s] a device which has the capacity to structure our conceptual system. Metaphor provides a particular understanding of the world and the way to make sense of the experiences we have. Thus, Lakoff (1994: p. 203) defines metaphor as "a cross-domain mapping in the conceptual system." In other words, a set of conceptual correspondences is from a source domain to a target domain. A good example is the metaphor DEATH IS A JOURNEY in which mapping projects attributes of the source domain (departure, arrival, climbing, descending, etc.) onto the taboo target domain of death. Thus, the source domain is employed to understand as well as structure and even in some cases mitigate the target domain. According to Jäkel (2002), most metaphorical expressions must be treated as linguistic realization of conceptual metaphors rather that treating them in isolation. Conceptualization fulfils its euphemistic function, precisely, in this correspondence between the source and the target domains (Fernández, 2008: p. 88).

In the current study of metaphor-based euphemisms, euphemistic expressions in the source domain are employed to replace the culturally taboo and unpleasant expressions in the target domain. A cognitive approach to the analysis of euphemistic expressions helps in explaining the mechanism of euphemizing.

\section{Euphemism and the Taboo of Death}

Allan \& Burridge (1991: p. 11) have done some extensive work on euphemism. 
According to them, euphemism refers to those expressions "used as an alternative to a dispreferred expression, in order to avoid possible loss of face: either one's own face, or, through giving offence, that of the offence, that of the audience, or of some third party". They opine that using euphemistic expression is " $[t]$ o use language like a shield against the feared, the disliked, the unpleasant" Allan \& Burridge (1991: p. 222). Fernández (2006) later confirms this, observing that euphemistic substitution is employed "[ $\mathrm{t}] \mathrm{o}$ mitigate the potential dangers of certain taboo words or phrases considered too blunt or offensive for a given social situation." In the opinion of Leech (1974: p. 53), euphemism has to do with "replacing a word which has offensive connotation with another expression, which makes no overt reference to the unpleasant side of the subject." The social benefits of euphemism are evident in the observation of Linfoot-Ham (2005: p. 228), that it allows discussion of taboo subjects without enraging or upsetting other people.

The apprehension, discomfort and fear that the subject of death brings to the living has been pervasive, since time immemorial, in different cultures. Thus, through superstition or respect many cultures refrain from using plain language in dealing with the subject, in order to soften the negative impact of what they actually wish to communicate. This is where euphemism is employed to strip taboo expressions of their offensive, vulgar and fear-inspiring overtones. Allan and Burridge (1991) observe that death is a "fear-based taboo", arguing that in the taboo of death different fears coexist, namely, fear of the loss of loved ones, fear of the corruption of the body, fear of evils [is it evil] spirits, and fear of what comes after death. In many cultures of the world, euphemism has been a common way of speaking about death taboos.

The Akan word for euphemism if kasambrani ${ }^{1}$, meaning "language used in covering up". Explaining euphemisms from the Akan perspective, Agyekum (2002: p. 372) observes that they are a sort of "shield against the offensive nature of taboo expressions." According to him, the Akan people conceive euphemisms as verbal art forms they employ to embellish speech to show communicative competence and linguistic politeness. Akans, expressing the same fears, express great discomfort with the subject of death. Therefore, they refuse to speak about it and when they do, they use euphemisms in speaking about it. They believe the mention of the word owuo "death" is to invite it to the living. Therefore, when a person dies, they rather choose to describe his or her state with euphemisms in order to reduce the discomfort and fear it invokes in the living. Akan death euphemistic expression is swathed in the consoling shroud of metaphoricity, to provide comfort for the loved ones of the deceased.

Finding it difficult to come to terms with death, the Akan language and the language of the Hebrew Bible express reluctance in dealing with the subject of death using straightforward terms. Therefore, both languages resort to euphem-

The term kasambrani is made up of three words, kasa, "language", the nominal prefix "m-", the verb bra, "cover", and the noun ani, "face". 
ism to somehow soften or conceal the fear and offense associated with death taboo. For them, it is a culturally polite way of speaking about death, an inevitable experience of humanity. So, what are the Akan and Hebrew death expressions that serve as a denial device against death? This study attempts to explore the death metaphors in both languages that serve as a powerful device for euphemistic reference.

\section{Death Metaphors in Akan and Hebrew-A Contrastive Approach}

Allan and Burridge (1991: p. 161) put euphemisms for death into four categories, namely 1) death as a journey, 2) death as beginning of a new life, 3) death as a loss and 4) worries about the soul. However, these authors do not explicitly apply the theoretical framework of the Conceptual Metaphor Theory (CMT). Under this theory, Lakoff and Turner (1989) identified the following metaphors for death: DEATH IS A PERSON, DEATH IS LOSS, DEATH IS DEPARTURE, DEATH IS A FINAL DESTINATION, DEATH IS SILENCE, DEATH IS WINTER, DEATH IS NIGHT, DEATH IS DELIVERANCE, etc. The examples of linguistic expressions they give for this purpose include the expressions, "he passed away", "he's passed on", "he's left us", "he's gone", "he's no longer with us", "he's been taken away from us", "he's among the dear departed", "he's gone to the great beyond", etc. There is no doubt the same conceptual metaphors can be found in Akan. In this study, we deal with five major metaphors for death identified in Akan and Hebrew (DEATH IS LOSS, DEATH IS A JOURNEY, DEATH IS THE END, DEATH IS SLEEP/REST, and DEATH IS A PERSON. In the final section we will explore the personification of death. Since we are not interested in the frequency of certain death metaphors in discourse, our analysis of the selected DEATH metaphors in Akan and Hebrew is qualitative and not quantitative. Our aim is to establish whether the same euphemistic strategies by means of metaphors are employed in both languages.

The analysis in this study leans on DEATH metaphors in Akan gathered through personal knowledge of various Akan euphemistic expressions for death, personal interviews among fellow Akan people and everyday speech. The Hebrew data for this study are gathered for [from] the Hebrew Bible. The Hebrew data were then contrasted with the metaphorical mappings explained in Akan, to establish the possible similarities and differences in the euphemistic conceptualization of the target domain DEATH, between the Hebrew and Akan languages.

\subsection{Death as a Loss}

Survivors (relatives and loved ones) perceive death as a loss of life or a loss of a beloved one. This conceptualization of death leans on the conceptual metaphor, LIFE IS A PRECIOUS POSSESSION. In this metaphor, life is conceptualized as a priceless object that may be lost, wasted or stolen. The DEATH IS A LOSS metaphor may be instantiated by the following metaphorical expressions in Akan: 
[1] yen ayera adec, "we have lost a thing".

[2] wahwere ne nkwa, "he has lost his life".

[3] waka nkyene agu, "he has kicked salt away".

The Hebrew equivalent is as stated below:

[4פשה בצאת [4- "as her life was leaving her" (Gen. 35: 18).

In [1], it is the living that loses a loved one to death. In [2] and [3] it is the dead that loses something, that is the souls (nephesh) and taste respectively. This loss on the part of the dead is expressed in the Akan euphemism waka nkyene agu, "he has kicked salt away". For the Akan, the human being cannot live without tasting salt. The explanation for pushing salt onto the ground is that the dead has no sense of taste. Therefore, to the deceased salt which brings sweetness is waste, hence the coining of a euphemism with gustatory connotations to explain the separation between the dead and the living. The expression [4] is the description of the death of Rachel (Gen. 35: 18). The euphemism here indicates LOSS of life. Thus, LIFE IS A POSSESSION that can be lost.

Both languages characterize such a loss as unredeemable as shown by the following metaphorical expression; se owuo kura adec mu a nkwa rentumi ngye, "Life cannot snatch away what death holds". The Hebrew has... This conceptual metaphor is realized by similar metaphorical expressions both in Akan and Hebrew, therefore being shared in both languages at the cognitive and linguistic levels.

\subsection{Death as a Journey and Death as a Departure}

Conceptualization of DEATH IS A JOURNEY metaphor arises from the understanding of the domain of death in terms of the domain of journeys. The conventional structural metaphor LIFE IS A JOURNEY gives coherence to the conceptual metaphor DEATH IS DEPARTURE. Bultnick (1998) observes that human mortality is conceptualized as a departure from this world. He notes that a basic domain of experience like death is understood in terms of a different and more concrete domain, as a journey. There are three clear stages in the life span of a person: birth, life and death. As Ozcaliskan (2003: p. 284) vividly put it, "birth is conceptualised as arrival, life as a journey initiated by this arrival and death as a departure that ends the journey." Death is conceptualised as the end and destination of life's journey (Kövecses, 2002: p. 44). The departure is uni-directional, with no return (Lakoff \& Turner, 1989). However, in Akan, death is conceptualised as a JOURNEY, the final one ${ }^{2}$. The metaphorical mapping transfers different attributes from the source domain of a journey to the

${ }^{2}$ There are also Akan euphemisms for death which lend support to the metaphor, DEATH IS SEPARATION. Examples are (i) W adane ato ho, "he has dropped it" and Wagyae mu, "he has left it". Both expressions indicate that life is an object we hold firmly onto or cling to, therefore, death is "letting go". Also, wadi ako ats, "s/he has fought and fallen", lends support to the popular Akan saying, "LIFE IS WAR". This confirms the belief that the living is in a constant battle for the living, and death is an indication that one has lost the battle. DEATH IS LOSS, not only on the part of the survivors but on the part of the deceased as well. 
target domain of death.

1) We shall illustrate this with several euphemisms in Akan:

The Akan language uses various euphemisms to express the death of an ordinary person.

[5] waka baabi, "S/he is stranded somewhere".

This implies a person traveled somewhere and could not return or incapable of leaving his/her destination.

[6] wafiri $m u$, "S/he has moved out".

[7] Watwe (ne ho), "he has withdrawn".

[8] watwa n'ani ahwe ban, "he has turned the face towards the wall".

The expression in [5] waka baabi, means the departed soul is locked up somewhere upon embarking on his/her journey and cannot return. The expressions [6] wafiri $m u$ and [7] Watwe (ne ho), literally connote a departure from the midst of the relatives of the deceased. In Akan therefore the conceptual metaphor DEATH IS DEPARTURE, marked by the verb firi, "leave/depart", is manifested at the linguistic level. The expression [8] instantiates the metaphor DEATH IS A DEPARTURE. When people embark on a journey, they bid us farewell, turn their backs to us and leave us. A similar expression to [8] is wadane ne ho, literally, meaning "he has turned himself", which indicates an about-turn.

In the Akan tradition, the death of the king is expressed differently from that of any ordinary citizen or member of society. One extremely offensive death taboo expression is ohene awu, "the king/chief is dead" (Agyekum, 2010). Therefore, euphemisms are employed to describe his death. There are various expressions instantiating the DEATH IS A JOURNEY metaphor in reference to euphemisms employed for the death of a king or chief. Examples are:

[9] ohene ko akuraa, "the chief has gone to the village".

[10] sko ne kraakyi, "he has gone to his soul's origin".

[11] Nana atoa ne mpanimfos, "Nana has followed the elders".

[12] Nana aforosoro, "Nana ${ }^{3}$ has climbed the vault of the skies".

[13] nana ko aduro so, "Nana has gone to the medicine house".

[14] wayc Nyame dea, "s/he has become God's possession".

In each of these five euphemisms [9] [10] [11] [12] [13], the Akan refers to the event of somebody's death as departure, where death is an event and going, following and climbing in the respective euphemisms [9] [10] [11] [12] and [13] are deliberate actions. Such conceptualization is based on the metaphors STATES ARE LOCATIONS and CHANGES ARE MOVEMENTS, both metaphors forming part of EVENT STRUCTURE metaphors. In [10] oks ne kra akyi, (Agyekum, 2010), his soul's origin is the village from which his soul hails. That is where his owner is [14] waye Nyame dea, "s/he has become God's possession", instantiat-

${ }^{3}$ Nana basically refers to an elderly person, especially "grandparent". However, as a term imbued with respect, it is the title for King or chief. 
ing the metaphor DEATH IS ARRIVAL. The Akan believe those who embark on the journey of death will return. They believe that the king/chief goes on a short trip into the afterlife for medical treatment as expressed in the euphemism [13] nana $k$ aduro so. The understanding is that the departed king is just visiting the hospital in the underworld and he will soon come back through the process of rebirth.

2) In their used of euphemisms, Hebrew makes no distinction between the death of the ordinary person and that of their king. In Hebrew, there are various expressions instantiating the DEATH IS A JOURNEY metaphor. Some of these

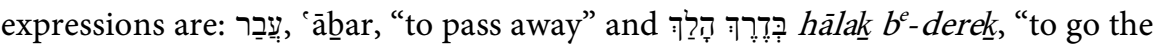
way". The conceptual metaphor DEATH IS DEPARTURE, marked by the verb עִבֵבר is the case where the event of someone's death is referred to as departure.

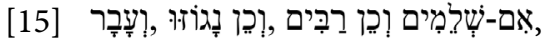

Though they be in full strength, and likewise many, even so shall they be cut down, and he shall pass away (Nahum 1: 12).

Another expression of the metaphor DEATH IS A JOURNEY IN THE He-

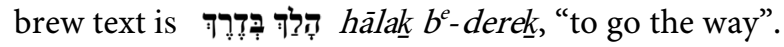

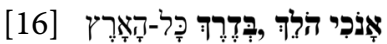

"I go the way of all the earth" (I Kg. 2: 2).

It is in this sense that David indicated on his deathbed, that he is embarking on the journey of the whole world, that is "all humans". Death is the destiny of all humanity and this is confirmed by the Akan expression owuo atwedec, sbaakon nforo, meaning, "all humankind will surely climb death's ladder". In the example above death is an event and passing is a deliberate action (Kövecses, 2002: p. 229).

The Akan euphemistic expression, [6] wafiri mu, "he has moved out" supports the CONTAINER image schema. Life is conceptualised as a container whose "structural elements [are] an interior, a boundary and an exterior, as well as an entrance point (Marin-Arrese, 1996: p. 47). In this sense death can be conceptualised as exiting a container (a body of relatives and friends or a community of the living) and at the same time an entry into another container (the world of the dead). In Akan traditional thought, the latter container representing the afterlife, is the world of the "living dead". The metaphorical expression also instantiates the metaphor DEATH IS A BOUNDARY. Thus, as Moreno (1998-1999: p. 292) observes, "being dead is being out of a bounded region, that is out of here." Thus, both the DEATH IS A JOURNEY and DEATH IS DEPARTURE conceptual metaphors are linguistically manifested in both the Akan and the Hebrew languages.

Akan euphemisms employ the knowledge about journey to talk about death since the act of dying corresponds to the act of departing and the destination of the journey is the abode of God ([14] wayc Nyame dea) and the abode of the an- 
cestors, nananom or mpanyimfo ([11] watoa ne mpanyimfo or nananom). The euphemistic substitutes include, foro, "to ascend", firi, "to leave" or "move out", $k$, "go away", toa, "to go to" or "catch up with". All these words indicate that death involves travelling. Consequently, the deceased is conceptualized as embarking on a journey. In Akan, death is conceptualized as a journey and it is assumed that all the bodily experiences of movements occur. This analogy implies that the cessation of bodily experiences is not automatically identified with the symptoms of physical death, since they are present in a journey. Thus, the conceptual metaphor DEATH IS A JOURNEY is thought to provide some kind of respite for surviving relatives and friends, that the deceased, though dead, is alive in a form of life where there is activity.

The Hebrew also conceptualizes death as travelling downwards to their destination, conventionally to a lower region called she' ol interpreted as the grave or the nether-world 4 . Upon arrival, the dead as "shades" will be at rest. Example of

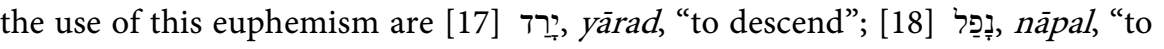
fall”.

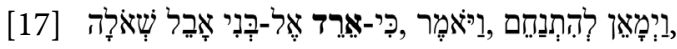

but he refused to be comforted; and he said: "Nay, but I will go down to the grave to my son mourning" (Gen 37: 35).

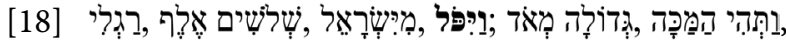

.... and there was a very great slaughter; for there, fell of Israel thirty thousand footmen (1 Sam. 4: 10).

The euphemistic expression in [17] and [18] indicate that [could it be that death is missing out] is a downward journey-DEATH IS DOWN. However, in the Akan euphemism DEATH IS UP as well as indicated in [12] Nana aforo soro.

The Akan expression wayc Nyame dea, "s/he has become God's property", [the expression s/he has become God's appears to translate the Akan expression waye Nyame dea better than s/he has become God's property as the latter may literary be translated as waye Nyame agyapade] is undergirded by the notion that God is grandparent. This is evident in description of God as Nana Nyame. Again, the euphemistic expression, watoa nananom, "gone to be with the ancestors" also implies literally, "to go to be with the fathers". The term nananom refers to "living grand-parents" or "grand-relatives who have departed". Thus, in Akan thought, death is conceptualized as a journey which ends upon arrival at the abode or "bosom" of God or the ancestors. Thus, there can be an extension of the metaphor DEATH IS A JOURNEY to include derivatives such as DEATH IS ARRIVAL and DEATH IS REUNION.

The Hebrew has similar euphemistic expressions suggesting the afore-mentioned

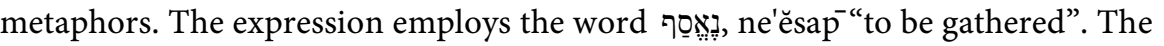
expression "gathered to his people" is recorded at the death of such great perso-

${ }^{4}$ See both Gen. 37: 35 and Job 17: 16. 
nalities in the Old Testament as: Ishmael (Gen. 25: 17), Isaac (Gen. 35: 29), Jacob (Gen. 49: 33), Aaron (Num. 20: 24), Moses (Deut. 33: 50), Josiah (2 Kgs. 22: 8). A close variant is the expression "gathered to one's fathers". Examples are:

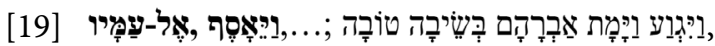

"And Abraham expired, and died in a good old age... and was gathered to his people" (Gen 25: 8).

[20]

"And also, all that generation were gathered unto their fathers".

In both [19] and [20] above, the Hebrew notion is evident, that upon arrival, the departed reunites with their relatives or fathers who have gone ahead of them. Note also a metaphor of REUNION in the use of the death term "to be joined" or "united", often with such additions as "to his people", "tribe", "fathers", or "to his grave".

In this section, we discover that both the Akan and the Hebrew have a common euphemistic presentation of death as a journey. The DEATH IS DEPARTURE, DEATH IS ARRIVAL and DEATH IS REUNION further clarify what the general metaphor, DEATH IS A JOURNEY, comprises. Here could be seen an image-schema of a ROAD that explains the Akan and Hebrew understanding of death as travel, whose limits-the starting point and the end point (the former indicating departure at the moment of dying, and the letter, reuniting with those who have gone ahead of them). We realize that in both the Akan and Hebrew languages, the conceptual basis for JOURNEY metaphors respond to a general view of death in terms of departure, arrival and reunion.

\subsection{Death as the End}

According to Johnson (1987: p. 117), the passage of time is generally understood on the basis of movement along a physical path, with the course of processes being understood as a movement along a path to some end point. Lakoff (1994: p. 232) observes that the passage of time will eventually result in death, hence the conceptualization of death reaching an end point. To linguistically demonstrate their understanding of this end point in spatial terms, the Hebrew employ metaphorical expressions such as: קי, qeẹs, "end", אין, 'yin, "is not", "is no more"

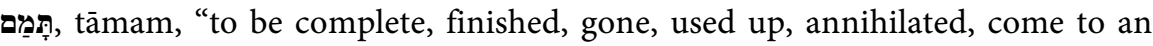
end".

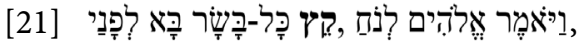

"And God said unto Noah, the end of all flesh is come before me" (Gen 6:

$13)$.

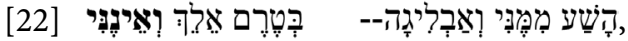

"Look away from me, that I may take comfort, before I go hence, and be no more" (Psalm 39: 14).

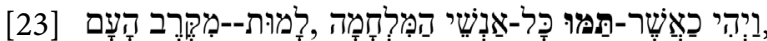


So, it came to pass, when all the men of war were consumed and dead from among the people (Deut 2: 16).

The corresponding Akan linguistic instantiation of the DEATH IS THE END metaphor is the expression, as â, "it is finished".

\subsection{Death as Sleep/Rest}

The conceptualization of DEATH as SLEEP is very present in both Akan and Hebrew thinking.

In the representation of metaphor by the A IS B formula, the "IS" represents a partial mapping from one domain to another and does not necessarily represent equivalence. According to Lakoff and Turner (1999: p. 67), the conventional metaphor, DEATH IS SLEEP “does not map everything in our general knowledge of sleep onto death but only certain aspects: inactivity, inability to perceive, horizontal position and so on". The Akan expression, se wo nnim owu a hwe nna, "if you don't know what death is, then look at sleep", agrees with the assertion of Ozcaliskan (2003: p. 302), that "the appearance of a sleeping person resembles that of a corpse, with its silence, coldness and stillness." It is evident that the features of a sleeping person mimic the features of a dead person, a universal perception which has led to several death metaphors both in Akan and Hebrew. In Akan, the idea of $d a$ "sleep" is to lie down. Here are some examples of the DEATH IS SLEEP metaphor from Akan.

[24] sdae a wanssre,

"When s/he slept s/he did not wake up".

[25] wada ne ketc akyi,

"S/he has slept at the back of his/her mat".

[26] wada ne bankum so

"S/he has slept on his/her left side".

Lakoff and Turner (1989: p. 19) observe that "just as death is a particular departure, a one-way departure with no return, so death is particular sort of sleep, an eternal sleep from which we never waken." In Hebrew thought, the place where a dead person interred is conceptualised as its place of perpetual sleep.

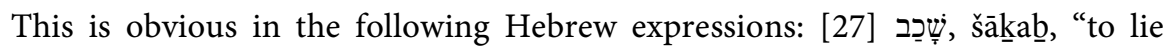

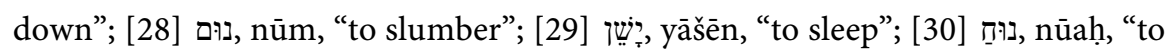

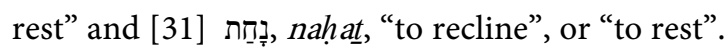

${ }^{5}$ In Akan, left is sinister, weak, filthy, inferior, defective, ugly, bad, misfortune, worthless, disrespect, and all sorts of insoluble problems. While the word nifa, "right" evokes most of the ideas contrary to these. In Ghana, one should not even pass or receive something from an elderly person or a superior with your left hand. One proverb reveals how offensive it is to point at one's father's house with the left hand. The reason is largely because the left hand is associated with bodily functions, so it is considered to be dirty and inferior to the right. However, a stranger who makes such a mistake for the first time is forgiven. Among the Akan, there is a notion that the left is the "side of death" and the right id the "side of life". Hence, the euphemistic expression for death, wada ne bankum so, "he has slept on his left side". 


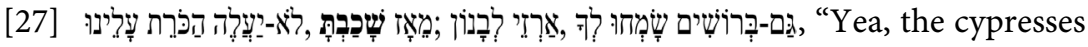
rejoice at thee, and the cedars of Lebanon: "Since thou art laid down, no feller is come up against us" (Isa. 14: 8) ${ }^{6}$.

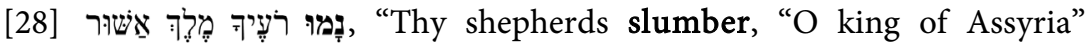
(Nah. 3: 18).

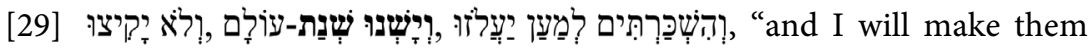
drunken, that they may be convulsed, and sleep a perpetual sleep, and not wake..." (Jer 51: 39) ${ }^{7}$.

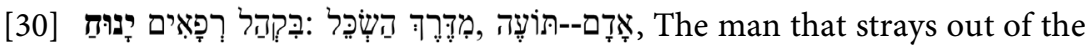
way of understanding shall rest in the congregation of the shades." (Prov 21: 16).

[31] "They shall go down to the bars of the nether-world, when we are at rest together in the dust." (Job 17: 16).

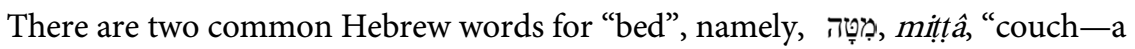

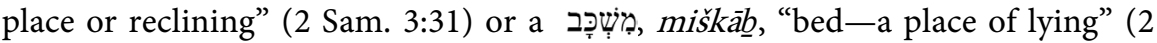
Chron 16: 14$)^{8}$. The dead body lying in state is euphemistically referred to as

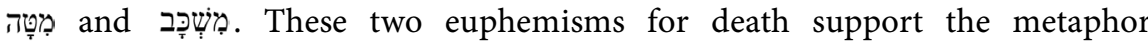
DEATH IS REST/DEATH IS SLEEP'.

In both Akan and Hebrew euphemisms, death is viewed as "sleep" and "rest". The attributes associated with sleep are used in structuring death as they are transferred from the domain of sleep to the domain of death. The conceptualization of DEATH AS SLEEP portrays death as a quiet sleep or repose after earthly existence. These euphemisms demonstrate a positive view of and attitude towards death. This section reveals that there are similarities in the linguistic realization of the DEATH IS SLEEP metaphor in Akan and Hebrew.

\subsection{Death as a Person}

Personification is a type of ontological metaphor. According to Lakoff \& John-

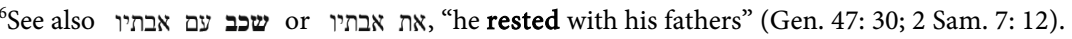

${ }^{7}$ The dead are also referred to as "שני אדמה עפר "that sleep in the dust of the earth" (Dan. 12:2) and שוכני עפר, "that dwell in the dust" (Isa. 26: 19). Here is a conceptualization of dust as DESTINATION and HOME/COUNTRY. Also, the expression ירד שאלה, "go down to she ol" (Gen. 37: 35) indicate that she'ol is DESTINATION/HOME. The Hebrew euphemistic expression, ישן שנת עולם "sleep the eternal sleep" (Jer. 51:39,57), demonstrate the concept of death as a journey of no-return.

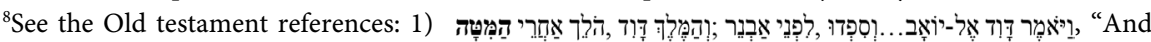
David said to Joab... wail before Abner". And king David followed the bier (2 Sam. 3: 31), 2)

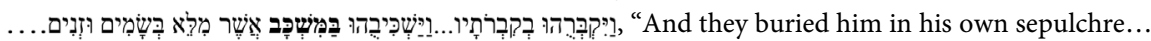
and laid him in the bed which was filled with sweet odours and divers kinds [of spices]...” (2 Chron. 16: 14).

${ }^{9}$ For Kövecses (2002: p. 52), the perception of death as "the utmost human disability in which we are blind, deaf, dumb, immobile, etc.", supports the identification of death with sleep by means of the SLEEP IS PHYSICAL DISABILITY metaphor. The cessation of a bodily function such as speech when sleeping might be the explanation of the Hebrew euphemism for death: (The dead praise not the LORD, neither any that go down into silence (Psalm 115: 17). the That the dead is dumb instantiates the metaphor DEATH IS SILENCE. 
son (1980: p. 33), personification permits us to understand "a wide variety of experiences with nonhuman entities in terms of human motivations, characteristics and activities. According to the generic-level metaphor EVENTS ARE ACTIONS, events are viewed as produced by an active, willful agent (Kövecses, 2002: p. 50). It is this event that is personified. In Akan, death is personified in the form of a ruthless and uncompromising tree-feller, a reaper who has no regard for anyone, not even for royalty.

This Akan perception support the assertion that such personification of death "exists by virtue of the PEOPLE ARE PLANTS metaphor, in which people are plants which are harvested by the reaper" (Lakoff \& Turner, 1989: p. 16). The conceptualization of death as a tree feller may be illustrated by the euphemistic expression of the death of a king,

[32] odupon kese atutu, "a mighty tree has fallen (literally, uprooted)"10.

[33] Ade ato m'ani, "an object has fallen into my eye".

In Akan conception of life, people are plants and their king is the most gigantic tree among them. He is the protector and helper they look up to. The expression in [32] is used for departed kings or chiefs and not for ordinary people. Therefore, his fall spells disaster. Besides, as Kövecses (2002: p. 229) puts it, "[d]eath is an event and this event can be conceptualized as an action via the EVENTS ARE ACTIONS metaphor." The event, in the case of Akan conceptualization of the death of the king, is uprooting or felling a person as if $s /$ he is a tree. In other words, death causes fall, as expressed in another Akan euphemism for death, Wats fam, "S/he has fallen on the ground". The two euphemisms "A mighty tree has been uprooted" and "S/he has fallen on the ground" instantiate the metaphors DEATH IS A FALL. Such is the personification of death by virtue of the PEOPLE ARE PLANTS metaphor in which trees correspond with kings who can be uprooted by the tree-feller. Here DEATH IS A PERSON, a WORKER who uproots trees ${ }^{11}$. Thus, in Akan, life is conceived as being firmly planted in the ground, and dying is "being dug out of the ground".

In [33], the understanding is that the bereaved person sheds tears as if something has been dropped into his or her eye. When death snatches a loved one away, it is as if it has cast an object into the eyes of the living relatives and friends. Such a euphemism instantiates the metaphor DEATH IS A THROWER OF OBJECTS INTO EYES. Thus, DEATH IS A PERSON.

\footnotetext{
${ }^{10} \mathrm{~A}$ similar metaphor is beps $\mathrm{w}$ kese atutu, in this euphemistic expression the king is conceptualized as bepow kese, "gargantuan mountain". That this mighty mountain has fallen suggests an Akan botanomorphic imagery of a mountain as having roots. All citizens are landforms, their king is the landform with the highest peak. For him to be uprooted is catastrophic and only death can dig up this mountain. Only death can cause that which is standing firm to fall flat. DEATH IS AN EARTH-MOVER.

${ }^{11}$ Based on the metaphor DEATH IS A PERSON, death is endowed with characteristics of a human being. There is a metaphorical expression in Akan where "death in a personified form causes the departure of the person from life" (Ozcaliskan, 2003: p. 292), e.g. owuo abefa no aks, "death has taken him/her away", however, this expression which mentions death "owuo" directly is not euphemistic.
} 
In the Akan conceptualization of death as a person the euphemistic expression in [12] Nana aforo soro, which refers to the king climbing into the skies, is very relevant in our discussion. In Akan Adinkra symbols, the ladder represents the metaphorical expression owuo antwedec, sbaako nforo, "Everyone will climb the ladder of death". In Ghana, one finds in the village where people die at home, a surviving relative giving water to the dying in order to, so to speak, ease the dying person's painful gasping for breath while climbing up in death. This conceptualizing of dying as climbing a ladder agrees with the euphemism, Nana aforo soro, thereby suggesting the destination of the traveling dead person somewhere in the skies. Both euphemisms instantiate the metaphor DEATH IS UP. Thus, DEATH IS A JOURNEY, a travel UP into the skies. Also, as a WORKER whose job is to usher the dead into the afterlife, DEATH IS A GRIM ESCORT who carries the ladder by which the dead climb into their destination somewhere in the skies. The ladder becomes the path bridging this life and the afterlife, and death is so to speak, the traffic warden.

Death in a personified form is also conceptualized as an escort in the euphemistic expression, [14] waye Nyame dea, "s/he has become Gods' property". This euphemism suggests that God the creator owns all life and that all dead persons belong to him. He owns both the living and the dead. When a person dies, s/he becomes fully God's possession. Thus, death does not necessarily undermine and revoke the identity of the dead as property of the creator. Death hands over to God what is God's by ushering a person to his or her owner.

In the Hebrew, death is conceptualized as sweeping away dirt, as indicated in

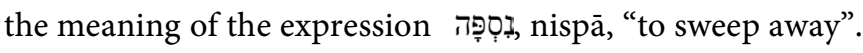

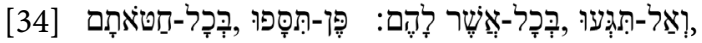

"and touch nothing of theirs, lest ye be swept away in all their sins" (Num.

16: 26).

This Hebrew euphemism here instantiates the metaphor DEATH IS A WORKER. In this passage, breakers of God's commandments are moral garbage, littering the midst of the obedient and death cleans them off-DEATH IS A SWEEPER.

In both the Hebrew and Akan languages, we see metaphorical expressions in which death appears in a personified form. This instantiates the metaphor DEATH IS A PERSON, whose job description includes, for the Akan, felling trees, throwing objects into eyes, carrying ladders for traffic management, and for the Hebrew, sweeping. As Lakoff and Johnson (1980: p. 34) puts it, "personifications are employed "to make sense of phenomena in the world in human terms... terms that we can understand on the basis of own motivations, goals, actions and characteristics." Again, according to Kövecses (2002: p. 39) the EVENTS ARE ACTIONS metaphor accounts for many cases of personification. This suggests that death is an action that is performed by an agent. 


\section{Conclusion}

In this paper, I have attempted to outline the implications underlying the use and interpretation of death metaphorization within the framework of the Conceptual Metaphor Theory initiated by Lakoff \& Johnson (1980). The present study has provided evidence that euphemisms used to refer to death taboo are well accounted for in terms of the Conceptual Metaphor Theory. It is evident from the analysis that death is a subject that is cautiously spoken about in both Akan and Hebrew.

Metaphors have the ability to conceal or highlight; therefore it should not be strange that euphemisms in both Hebrew and Akan are frequently packaged in conceptual metaphors as one of the useful devices of forming euphemisms. The study in this paper has attempted to contrastively analyze numerous metaphors for death in Hebrew and Akan to establish whether both languages utilize the same euphemistic reference in dealing with the taboo of death. In almost every culture of the world people attempt to shut off the thought of death in their minds and therefore employ metaphor-based mechanisms to deny unpleasant and dreadful experiences. The same is true of the Akan and the Hebrew. As we have seen in this paper, the function of metaphors in euphemistic reference has been demonstrated as being very significant in both languages. Through our analysis, it is evident that Hebrew and Akan share the same conceptual mappings regarding mortality. This is obviously rooted in the universal understanding that DEATH metaphors are deeply ingrained in our physical and bodily experience.

The evidence provided by this study supports the claim that members of different cultures cannot conceptualize a universal experience "in a way that contradicts universal physiology", but can conceptualize it "within the constraints imposed on them by universal physiology" Kövecses (2007: p. 165). In our data, the metaphors DEATH IS LOSS, DEATH IS THE END, DEATH IS SLEEP, DEATH IS A JOURNEY AND DEATH IS A PERSON indicate that in both Hebrew and Akan, death hides itself behind cautiously constructed metaphors on both the Akan and Hebrew languages.

The analysis undertaken shows that euphemistic expressions referring to death taboos can be described in terms of Lakoff and Johnson (1980) cognitive view of metaphors. However, the analysis in this study is by no means exhaustive for the area of biblical studies. Research into further comparative study may be needed in revealing the linguistic and cultural differences in the euphemistic conceptualization of death in Akan and Greek (with specific reference to the Greek of the New Testament). It would also be revealing to contrast the results obtained in this research with some other Africa language in order to find conceptual and linguistic differences or similarities.

\section{Conflicts of Interest}

The author declares no conflicts of interest regarding the publication of this paper. 


\section{References}

Agyekum, K. (2002). Menstruation as a Verbal Taboo among the Akan of Ghana. Journal of Anthropological Research, 58, 367-387. https://doi.org/10.1086/jar.58.3.3631182

Agyekum, K. (2010). Akan Verbal taboos in the Context of the Ethnography of Communication. Accra: Ghana Universities Press.

Allan, K., \& Burridge, K. (1991). Euphemism and Dysphemism: Language Used as Shield and Weapon. Oxford: Oxford University Press.

Bultnick, B. (1998). Metaphors We Die by: Conceptualization of Death in English and their Implications for the Theory of Metaphor. Antwerpen: Universiteit Antwerpen.

Evans, V., \& Green, M. (2007) Cognitive Linguistics: An Introduction. Edinburgh: Edinburgh University Press.

Fan, Z. (2006). The Mechanism of Euphemism: A Cognitive Linguistic Interpretation. US-China Foreign Language, 4, 71-74.

Fernández, C. (2006). The Language of Death: Euphemism and Conceptual Metaphorization in Victorian Obituaries. Sky Journal of Linguistics, 19, 101-130.

Fernández, E. C. (2008). Sex-Related Euphemism and Dysphemism: an analysis in Terms of Conceptual Metaphor Theory. AtlantisJournal of Spanish Association of Anglo-American Studies, 30, 95-110.

Gibbs, R., \& Steen, G. (Eds.) (1999). Metaphor in Cognitive Linguistics (pp. 1-8). Amsterdam: John Benjamins. https://doi.org/10.1075/cilt.175.01ste

Jäkel, O. (2002). Hypothesis Revisited: The Cognitive Theory of Metaphor Applied to Religious Text. Metaphorik.de, 2, 20-42.

Johnson, M. (1987). The Body in the Mind: The Bodily Basis of Reason and Imagination. Chicago, IL: University of Chicago Press. https://doi.org/10.7208/chicago/9780226177847.001.0001

Kövecses, Z. (2002). Metaphor: A Practical Introduction. Oxford: Oxford University Press.

Kövecses, Z. (2003). Metaphor and Emotion: Language, Culture and Body in Human Feeling. Cambridge: Cambridge University Press.

Kövecses, Z. (2007). Metaphor and Emotion. Cambridge: Cambridge University Press.

Lakoff, G. (1987). Women, Fire and Dangerous Things. Chicago, IL: Chicago UP. https://doi.org/10.7208/chicago/9780226471013.001.0001

Lakoff, G. (1994). The Contemporary Theory of Metaphor. In A. Ortony (Ed.), Metaphor and Thought (pp. 202-251). Cambridge: Cambridge University Press. https://doi.org/10.1017/CBO9781139173865.013

Lakoff, G., \& Johnson, M. (1980). Metaphors We Live by. Chicago, IL: Chicago University Press.

Lakoff, G., \& Johnson, M. (1999). Philosophy in the Flesh: The Embodies Mind and Its Challenge to Western Thought. New York: Basic Books.

Lakoff, G., \& Turner, M. (1989). More than Cool Reason-A Field Guide to Poetic Metaphor. Chicago, IL and London: The University of Chicago Press. https://doi.org/10.7208/chicago/9780226470986.001.0001

Leech, H. (1974). Semantics. Harmondsworth: Penguin.

Linfoot-Ham, K. (2005). The Linguistics of Euphemism: A Diachronic Study of Euphemism Formation. Journal of Language and Linguistics, 4, 227-263.

Marin-Arrese, J. I. (1996). To Die, to Sleep-A Contrastive Study of Metaphors for Death and Dying in Englkish and Spanish. Language Sciences, 18, 37-52. 
https://doi.org/10.1016/0388-0001(96)00006-X

Moreno, F. (1998-1999). Time, Life and Death Metaphors in Shakespeare's Sonnets: The Lakoffian Approach to Poetic Metaphors. RESLA, 13, 287-304.

Murphy, P. F. (2001). Studs, Tools and the Family Jewels. Metaphors Men Live by. Madison and Wisconsin, WI: The University of Wisconsin Press.

Nyakoe, D. G. et al. (2012). Conceptualization of "Death Is a Journey" and Death as Rest' in EkeGusii Euphemism. Theory and Practice in Language Studies, 2, 1452-1457. https://doi.org/10.4304/tpls.2.7.1452-1457

Otoo, R. (2017). Metaphorical Extensions of Ye (Eat) Verb: The Case of Ga. International Journal of Linguistics, 9, 132-145. https://doi.org/10.5296/ijl.v9i6.12104

Ozcaliskan, S. (2003). In a Caravanserai with Two Doors I Am Walking Day and Night: Metaphors of Death and Life in Turkish. Cognitive Linguistics, 14, 281-320. https://doi.org/10.1515/cogl.2003.012

Pfaff, K. L., Gibbs, R., \& Johnson, M. D. (1997). Metaphor in Using and Understanding Euphemism and Dysphemism. Applied Psycholinguistics, 18, 59-83. https://doi.org/10.1017/S0142716400009875

Ungerer, F. H., \& Schmid, H. J. (1996). An Introduction to Cognitive Linguistics. London \& New York: Longman. 